\title{
A simulation study of outpatient scheduling with multiple providers and a single device
}

\author{
Xiao-Dan $\mathrm{Wu}$ \\ School of Management, Hebei University of Technology \\ Tianjin, China \\ wxdan2000@yahoo.com.cn \\ Mohammad T. Khasawneh \\ Systems Science and Industrial Engineering, State University of New York at Binghamton \\ Binghamton, New York 13902, U.S.A. \\ mkhasawn@binghamton.edu \\ Dian-Min Yue \\ School of Management, Hebei University of Technology \\ Tianjin, China \\ Ya-Nan Chu \\ School of Management, Hebei University of Technology \\ Tianjin, China \\ Zhan-Ting Gao \\ Systems Science and Industrial Engineering, State University of New York at Binghamton \\ Binghamton, New York 13902, U.S.A.
}

Received 16 December 2013

Accepted 15 March 2014

\begin{abstract}
Effective outpatient appointment scheduling aims at reducing patient waiting time and operational costs, and improving resource utilization, especially given the stochastic nature of patient arrivals. Unlike many western developed countries, China faces challenges due to imperfect appointment systems and ineffective resource allocation. Those challenges lead to long patient waiting times and significant pressure to provide accurate and reliable medical diagnosis that can handle the increasing demand for patient care. In this paper, an outpatient appointment scheduling model for primary care settings was developed. The model was structured for a multiprovider clinic with a single medical device that allows for revisit (i.e., follow-up) procedures. A total of six scheduling rules were designed and tested. Then, sensitivity analysis was performed with respect to two parameters: the percentage of patients with fixed appointments and walk-ins, and the scheduled physician assessment times. The experimental results of the simulation model were used to determine the optimal values for the two parameters. Among the six scheduling rules tested, the one that involves patients with fixed appointments and walk-ins to be served alternatively every hour, led to the shortest waiting time and the highest equipment and staff utilization. In this scenario, patients with fixed appointments are served by Provider 1, while walk-ins are served by Providers 2 and 3. The sensitivity analysis under this rule revealed that when the percentage of patients with fixed appointments and walk-ins was $30-70 \%$, and the scheduled service time was 20 minutes, the total patient waiting time and total resource idle time were minimized.
\end{abstract}

Keywords-Multi-provider clinics, device utilization, outpatient scheduling, patient waiting time, patients scheduling rules, walk-in patients. 


\section{Introduction}

As the world economy develops increasingly fast, the state of population health and well-being becomes a progressively critical issue. However, unlike some developed countries, the state of the healthcare system in China is deteriorating. In particular, there are significant imperfections in appointment systems, a shortage of medical resources, and ineffective allocation of resources. In outpatient clinics, for example, the randomness associated with patient arrivals and physician assessment/treatment times, the need for more reliable health assessments, and non-standardized medical followup rules, lead to unnecessary complication in the healthcare system. Within this system, as patient demand increases, so does their wait time, an interaction primarily due to limited capacities and resource unavailability. Subsequently, long wait times negatively impact the quality of patient care and, consequently, patient satisfaction. However, during non-peak times, clinical staff and equipment resources experience more idle time.

Due to the pressure to improve healthcare delivery and reduce costs, research on outpatient scheduling has become popular in the past decade or so. The primary goals of studying outpatient scheduling are to minimize patient waiting time, reduce medical costs, and improve resource utilization, by taking into account the stochastic nature of patient arrivals and providers' diagnostic characteristics. Appointment scheduling rules can be used to adjust and evenly distribute patient demand throughout the scheduling horizon.

In the Chinese healthcare system, the aforementioned challenges cause concerns with the reliability of clinical diagnosis, thereby often requiring patients to revisit their provider for more accurate diagnosis that are supported by further test results. Considering these issues, this research intends to develop an outpatient appointment scheduling model for multiple providers and single revisit (follow-up) procedures using discrete event simulation. Then, by using sensitivity analysis, the simulation model is used to determine the optimal appointment scheduling rules. The determined appointment rules have the potential to be implemented in larger clinics and hospitals.

The remainder of the paper is organized as follows. Section 2 provides a brief literature review, which introduces the state of outpatient clinics in China and research on outpatient scheduling abroad. Section 3 discusses the model development, as well as the necessary assumptions, parameters, performance measures, and scheduling rules. Section 4 presents an experimental design and analysis of the simulation results to evaluate the various scheduling rules developed. The last section provides conclusions and a discussion on limitations, as well as possible ideas for future work.

\section{Literature Review}

Patient arrivals in general hospitals have significant and obvious patterns. For example, peak demand usually occurs between June and August every year; the last week of every month; Monday and Tuesday of every week; and 9:00-11:00am every day. In general, the volume of patients arriving in the afternoon is relatively small $[1,2]$. Patients typically follow several procedures in the hospital when they visit their physician, including registration, waiting for a room, triage, physician assessment, paying fees, follow-up revisit appointments, and prescription filling at the pharmacy [3].

There are three peak stages in outpatient systems: registration, physician assessment, and examination. Patient flow time in the system typically ranges from approximately 1 to 2 hours, while the physician assessment time takes only 10 to 15 minutes. The largest portion of patient flow time is wasted in waiting and moving in the system. During peak time periods, patients have to wait for a long time not only before the initial physician assessment, but also for other ancillary services. The resulting long queues lead to congestion in waiting areas and overcrowding outside consultation rooms [4] On the other hand, value-adding times such as diagnosis and other clinical tests are very short.

To avoid the disorder resulting from centralized registration and fee payment, patient arrival patterns can be level-loaded throughout the day with an effective scheduling system. To achieve this goal, many general hospitals adopt appointment/scheduling rules, through which they can control the time and volume of patient arrivals in advance and adjust the number of devices and clinical staff accordingly [5]

Appointment scheduling in healthcare has been well established in western countries for several decades now. In general, there are two types of studies related to appointment scheduling: outpatient scheduling and surgical scheduling. In the scheduling literature, there are generally three kinds of patients considered: outpatient, inpatient, and emergency patients. Gupta and Denton [21] divided appointment scheduling research into three categories: primary care, specialty, and surgery appointments. They also summarized the complexity factors and the state of appointment scheduling problems [21]. A review of outpatient scheduling classifies them based on four attributes: problem definition and formulation, measures of performance, appointment system design, and analysis methodology [22]. 
Before decisions are made in an appointment system, one should first determine whether the system is static or dynamic. In static systems, all decisions are made prior to the start of a session, whereas in dynamic systems, appointment times are adjusted consistently as patients arrive for service. Most appointment scheduling studies assume static cases, which typically includes serving patients with identically distributed service times in a single session with one provider. Static systems can be complicated, with complexities that involve the number of providers, patient classification, patient no-show rates, service time, multi-steps, follow-up visits, etc. [23-25]. Most appointment systems in China are static in nature, wherein patients are given appointments ahead of time, but not for a specific time period. The factors discussed that are most commonly discussed in the literature are summarized in Table 1.

Identifying the appropriate measures for system performance facilitates an assessment of the scheduling rules for appointment systems. Those measures are typically categorized as cost, time, congestion, and fairness-based measures. Table 2 shows the most widely adopted measures in the literature. For time-based measures, a system where 20 patients wait for 2 minutes each is not the same as one in which a patient waits for 40 minutes [28]. Typical time-based measures are patient waiting time, provider idleness, and staff overtime. Congestion measures, which are more concrete, indicate features such as overcrowding and queue length. Fairness measures refer to the even distribution of patients waiting evenly over the entire session time [29]. In China, the most salient problems are long waiting times and uneven utilization of resources; thereby making them the most frequently chosen measures with which to assess appointment rules.

The development of an appointment system has three stages: traditional model, carve-out model and advanced access model. In Table 3, a comparison of the three models is shown. The table indicates that the distinguishing point for each system is the fraction of open appointment slots every day [30]. In the traditional case, all slots are scheduled and patient waiting time varies from weeks to months. A carve-out model sets a small percent of unused slots aside for emergencies, whereas most slots are scheduled ahead of time. Therefore, long waiting time still exists. Advanced access model sets most slots free and only a small number are set apart for long lead time appointment or follow-up patients $[31,32]$

Appointment system design is guided by three parameters: 1) the "block", the number of patient arrivals at the start of an appointment; 2) the "initial block", the number of patient arrivals for the first appointment; and 3) the "interval", the appointment length, which can be either fixed or variable. Combining these attributes leads to a variety of appointment systems, as shown in Table 4.

Table 1. Healthcare scheduling literature review.

\begin{tabular}{|c|c|c|}
\hline \multirow{11}{*}{$\begin{array}{l}\text { Service Time } \\
\text { Distribution }\end{array}$} & \multirow{3}{*}{$\begin{array}{c}\text { General } \\
\text { Exponential }\end{array}$} & Lindley $(1952)^{[6]}$ \\
\hline & & $\operatorname{Mercer}(1973)^{[7]}$ \\
\hline & & Soriano $(1966)^{[8]}$ \\
\hline & Gamma & Fries \& Marathe $(1981)^{[9]}$ \\
\hline & Negative & Liao et al. $(1993)^{[10]}$ \\
\hline & $\begin{array}{l}\text { exponential } \\
\text { Frlang }\end{array}$ & Liu \& Liu (1998b $)^{[11]}$ \\
\hline & Erlang & Liu \& Liu (1998b) ${ }^{[11]}$ \\
\hline & $\begin{array}{l}\text { Weibull } \\
\text { Uniform }\end{array}$ & Mahacheck \& Knabe \\
\hline & Uniform & $(1984)^{[12]}$ \\
\hline & $\begin{array}{l}\text { Possion } \\
\text { Person Tyne III }\end{array}$ & Bailey $(1952)^{[13]}$ \\
\hline & $\begin{array}{l}\text { Person lype 1II } \\
\text { Lognormal }\end{array}$ & $\begin{array}{c}\text { Welch \& Bailey }(1952)^{[14]} \\
\text { O'Keefe }(1985)^{[15]}\end{array}$ \\
\hline \multirow{3}{*}{$\begin{array}{l}\text { No-shows (No- } \\
\text { show Probability) }\end{array}$} & $\begin{array}{c}0.04-0.22 \\
01\end{array}$ & $\begin{array}{c}\text { Fetter \& Thompson } \\
(1966)^{[16]}\end{array}$ \\
\hline & $\begin{array}{ccc}0.1 & \\
0.09 & 0 & 0\end{array}$ & Liu \& Liu (1998b) $)^{[11]}$ \\
\hline & $0,0.09,0.19$ & White \& Pike $(1964)^{[17]}$ \\
\hline Walk-ins & $\begin{array}{l}\text { Exponential } \\
\text { Negative } \\
\text { exponential }\end{array}$ & $\begin{array}{l}\text { Swisher et al. }(2001)^{[18]} \\
\text { Rising et al. }(1973)^{[19]}\end{array}$ \\
\hline \multirow{3}{*}{$\begin{array}{c}\text { Provider's } \\
\text { Lateness and } \\
\text { Interruption Level } \\
\text { (Gap Time) }\end{array}$} & $\begin{array}{l}0,5,10,1520 \mathrm{~min} \\
\text { late to first }\end{array}$ & White \& Pike $(1964)^{[17]}$ \\
\hline & $\begin{array}{l}\text { appointment } \\
\text { 0,30,60min late to } \\
\text { first appointment }\end{array}$ & $\begin{array}{l}\text { Fetter \& Thompson } \\
\qquad(1966)^{[16]}\end{array}$ \\
\hline & FCFS & \\
\hline \multirow{3}{*}{ Queue Discipline } & $\begin{array}{l}1^{\text {st }} \text { priority given to } \\
\text { emergencies or }\end{array}$ & Lindley $(1952)^{[6]}$ \\
\hline & patients returning & \\
\hline & $\begin{array}{l}\text { from X-ray, etc.; } 2^{\text {nd }} \\
\text { scheduled patients } \\
\text { and } 3^{\text {rd }} \text { walk-ins. }\end{array}$ & Rising et al. $(1973)^{[19]}$ \\
\hline \multirow{3}{*}{$\begin{array}{l}\text { Number of } \\
\text { Providers }\end{array}$} & Single 1 & Lindley $(1952)^{[6]}$ \\
\hline & Multiple (3) & Liu \& Liu (1998b) $)^{[11]}$ \\
\hline & & $\begin{array}{c}\text { Brahimi \& Worthington } \\
(1991 \mathrm{a})^{[20]}\end{array}$ \\
\hline
\end{tabular}

Table 2. Frequently used scheduling performance measures.

\begin{tabular}{lc}
\hline & Lindley $(1952)^{[6]} ;$ \\
Patient Waiting Time (Cost) & Jannson $(1966)^{[26]} ;$ \\
Liu \& Liu $(1998 \mathrm{~b})^{[11]}$ & Mercer $(1973)^{[7]}$ \\
Queue Length & Fries \& Marathe $(1981)^{[9]} ;$ \\
Provider Idleness (Cost or & Liu \& Liu $(1998 \mathrm{~b})^{[11]}$ \\
Utilization) & Fries \& Marathe $(1981)^{[9]} ;$ \\
Staff Overtime (Cost) & Liu \& Liu $(1998 \mathrm{~b})^{[11]}$ \\
Patient Flow Time & Wang $(1993)^{[27]}$ \\
Provider Completion Time & Wang $(1993)^{[27]}$ \\
Patient Throughput & Fetter \& Thompson \\
\hline
\end{tabular}


For example, the Individual-block/Fixed-interval has a relatively simple design, wherein each block has one patient and the interval is fixed. Currently, there is literature that focuses on Multiple-block/Variableinterval [33]. At the same time, patient types can further complicate the system, so that potential no-shows and service times can be better estimated [34-36]. Most Chinese appointment systems are Multiple-block/Fixedinterval, which divides the whole session into identical intervals and assigns the same number of patients for each one.

The modeling approaches of outpatient scheduling can be classified into analytical and simulation studies. Analytical methods, such as queuing theory and linear/dynamic programming, focus on basic scheduling problems, but only consider a small fraction of complex factors, such as patient no-shows and walk-ins [36, 37]. However, simulation studies are often preferred because they optimize and compare scheduling under complicated settings [38, 39].
Table 3. Appointment system types.

\begin{tabular}{|c|c|c|}
\hline Type & Illustration & Literature \\
\hline Single-block & 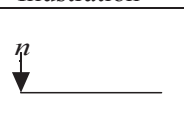 & $\begin{array}{l}\text { Kim \& Giachetti } \\
\quad(2006)^{[40]} ; \\
\text { Muthuraman \& }\end{array}$ \\
\hline $\begin{array}{l}\text { Individual-block/Fixed } \\
\text { interval }\end{array}$ & tiz 11 & $\begin{array}{l}\text { LaGanga \& } \\
\text { Lawrence } \\
(2007)^{[42]}\end{array}$ \\
\hline $\begin{array}{l}\text { Multiple-block/Fixed- } \\
\text { interval }\end{array}$ & $m \begin{array}{ll}m & m\end{array}$ & $\begin{array}{l}\text { Cayirli et al. } \\
(2006)^{[43]}\end{array}$ \\
\hline $\begin{array}{l}\text { Individual-block/Fixed } \\
\text { interval with an initial } \\
\text { block }\end{array}$ & & $\begin{array}{l}\text { Green et al. } \\
(2006)^{[44]}\end{array}$ \\
\hline $\begin{array}{l}\text { Multiple-block/Fixed- } \\
\text { interval with an initial } \\
\text { block }\end{array}$ & 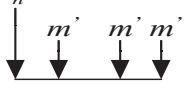 & $\begin{array}{l}\text { Gupta \& Wang } \\
\qquad(2007)^{[45]}\end{array}$ \\
\hline $\begin{array}{c}\text { Variable- } \\
\text { block/Variable-interval }\end{array}$ & $\begin{array}{ll}n_{2} & n_{3} \\
\downarrow & \downarrow\end{array}$ & $\begin{array}{l}\text { Fries \& Marathe } \\
\qquad(1981)^{[9]}\end{array}$ \\
\hline
\end{tabular}

Table 4.Outpatient appointment models.

\begin{tabular}{ccccc}
\hline Model & Scheduled Slots & $\begin{array}{c}\text { Walk-ins and } \\
\text { Emergencies }\end{array}$ & $\begin{array}{c}\text { Capability of } \\
\text { Clinics }\end{array}$ & Costs and Benefits \\
\hline Traditional Model & $100 \%$ & No & Low & $\begin{array}{c}\text { High cost, low benefit } \\
\text { Relatively high cost, low } \\
\text { benefit } \\
\text { Carve-out Model }\end{array}$ \\
Advanced Access Model & $<50 \%$ & Yes & Relatively high & High \\
Commonalities & $\begin{array}{c}\text { All have scheduled high benefit } \\
\text { slots }\end{array}$ & $\begin{array}{c}\text { All include walk-ins } \\
\text { and emergencies }\end{array}$ & $\begin{array}{c}\text { Considered } \\
\text { capability }\end{array}$ & $\begin{array}{c}\text { Lowest cost and highest } \\
\text { benefit }\end{array}$ \\
\hline
\end{tabular}

\section{Model Construction}

\subsection{System Description and Definition}

As stated earlier, this work focuses on walk-ins and patients with fixed appointment schedules. In outpatient systems, patient flow typically involves steps such as registration, waiting for room, triage, physician assessment, paying fees, examination, revisit, and prescription filling at pharmacy. In this paper, it is assumed that the appointment system consists of: patient arrival, physician assessment, examination, revisit, and checkout steps. The model is developed for a general internal medicine clinic that operates for 7 hours a day. As shown in Figure 1, the process flow starts with patients' arrival, when they wait for their appointment to see the doctor after they register. The provider then makes a decision whether the patient requires further physical test according to their condition, in which case the patient will have to wait again until the test results are obtained. Once the test results are available, the same provider will see the patient again to make a decision regarding their condition, after which he/she leaves the system. If a physical test is unnecessary, the patient can leave directly.

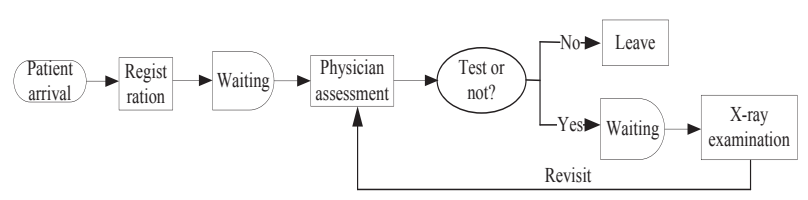

Fig.1. Patient flow process map

The current rules of outpatient clinic are relatively simple, as illustrated in Figure 2. Patient waiting starts after registration. When several patients are waiting for service at the same time, priority is ignored, and a first come the first serve (FCFS) rule is used. After physician assessment, patients either proceed to further testing or exit the system. Patients requiring further tests will wait again in a queue. During peak periods, patient waiting time and resource utilization are high. 


\subsection{Model Assumptions}

The following assumptions were made before constructing the model

(1) Both patients with fixed appointment schedules and walk-ins are taken into consideration.

(2) The system consists of multiple providers, and patients wait in a single queue, where the queuing discipline is FCFS.

(3) The system ignores patients who take medicine at outpatient clinics or require more than one physical examination. After service, patients leave or undergo an examination.

(4) Patients who require additional tests will revisit their former provider when the test results are ready. Each patient can revisit his/her provider only once, and their visiting time is fixed.

(5) Patients will wait for service regardless of queue length or waiting time duration, and all patients who arrive at the clinic will be seen by a provider.

(6) Human errors, tardiness, and no-shows are not taken into account in the model.

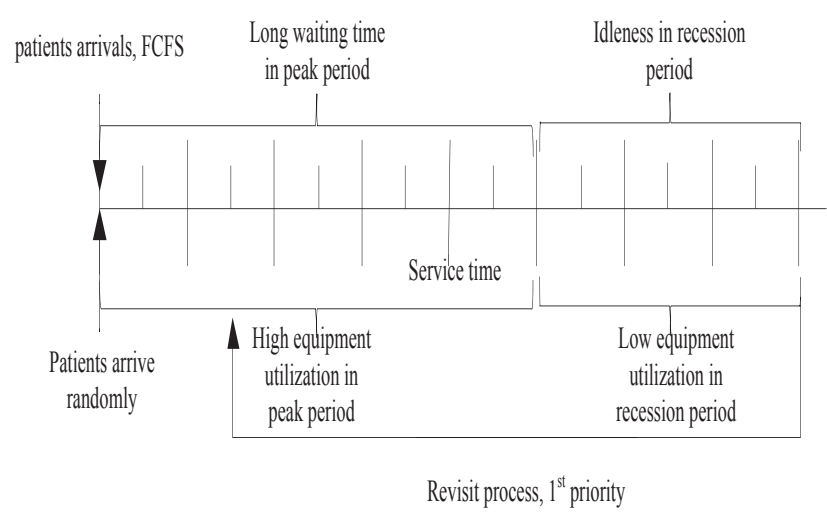

Fig. 2. Illustration of outpatient clinic service model

\subsection{Simulation Model Design}

The simulation model was developed using FlexSim Healthcare (HC). Within the chosen outpatient clinic, there are three providers and one chest X-ray device. The 3D model includes several entities, as shown in Table 5. In order to correctly and accurately match the model with reality, and compare the simulation results, it is necessary to set proper performance measures and parameters.

Table 5. Model entities and values.

\begin{tabular}{cc}
\hline Entity Name & Value \\
\hline Provider & 3 \\
Nurse & 3 \\
Patient arrival & 1 \\
Patient exit & 1 \\
Clinic & 3 \\
Device & 1 \\
Queue & 2 \\
\hline
\end{tabular}

This research studies appointment scheduling rules with multiple providers and a single device, as described in Figure 3. The total patient waiting time consists of the waiting time before seeing the provider for the first time $\left(\mathrm{DT}_{\mathrm{n}}\right)$, and the waiting time before seeing the provider for the second time for examination $\left(\mathrm{ET}_{\mathrm{i}}\right)$. Five parameters are considered: patient arrival pattern, physician assessment time, examination time, fraction of patients requiring a revisit, and chest X-ray. The probability distributions associated with these parameters were obtained after the data was processed, as shown in Table 6.

Performance measures are necessary to choose the optimal appointment rules. Patient waiting times should be minimized to improve patient satisfaction. The idleness of both the providers and the device should be minimized to save on cost and increase the utilization of resources. In this study, the purpose of outpatient scheduling is to minimize total waiting time and maximize resource utilization under the condition of unchangeable resources.

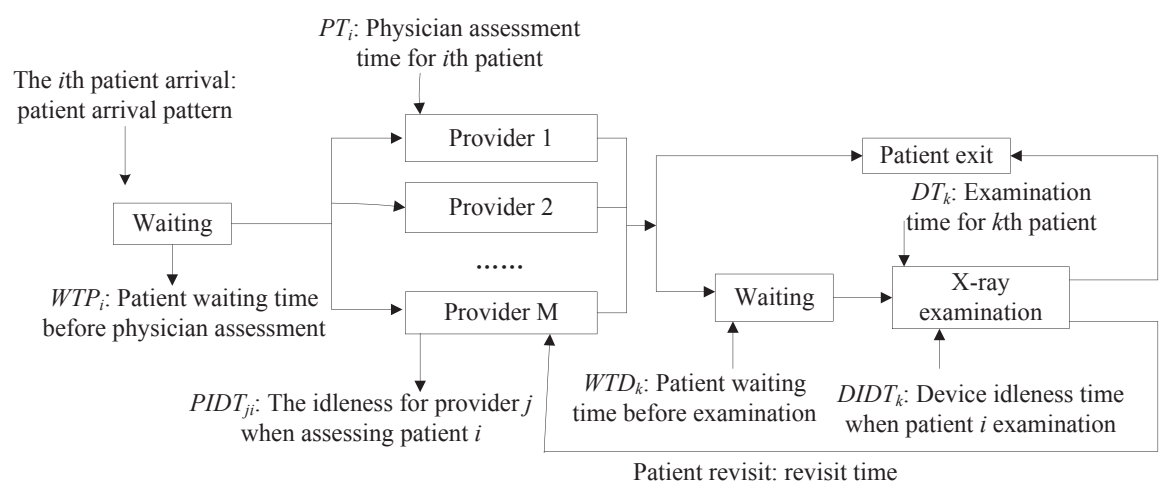

Fig. 3. System structure and parameters 
Therefore, three performance measures were chosen: patient total waiting time, and the resource idleness of both providers and the device. Figure 4 indicates the generation of patient waiting time and idleness, where the peak period occurs when $\mathrm{WTP}_{\mathrm{i}}$ and $\mathrm{WTD}_{\mathrm{k}}$ exist, which is when patients have to wait for long times before they can see the provider. The non-peak period occurs when PIDT $_{j i}$ and DIDT $_{\mathrm{k}}$ appear, where patient demands can be easily met, but resources are underutilized because of providers' and the device's idle times, resulting in higher operational and staff costs. A description of the parameters is shown in Table 7. The expressions for patient total waiting time (APWT) and total idleness (IDT) are as follows:

$$
\begin{gathered}
\text { APWT }=\frac{1}{\mathrm{~N}} \sum_{\mathrm{i}=1}^{\mathrm{N}} \mathrm{WTP}_{\mathrm{i}}+\frac{1}{\mathrm{n}} \sum_{\mathrm{k}=1}^{\mathrm{n}} \mathrm{WTD}_{\mathrm{k}} \\
\text { PIDT }=\sum_{\mathrm{j}=1}^{\mathrm{M}} \sum_{\mathrm{i}=1}^{\mathrm{N}} \text { PIDT }_{\mathrm{ji}} \\
\text { DIDT }=\sum_{\mathrm{k}=1}^{\mathrm{n}} \text { DIDT }_{\mathrm{k}} \\
\text { IDT }=\text { PIDT }+ \text { DIDT }
\end{gathered}
$$

Table 6. Parameter distributions

\begin{tabular}{cccccc}
\hline Parameters & Patient Arrival & $\begin{array}{c}\text { Service } \\
\text { Time }\end{array}$ & $\begin{array}{c}\text { Revisit } \\
\text { Time }\end{array}$ & Examination Time & $\begin{array}{c}\text { Fraction of patients } \\
\text { requiring examination } \\
\text { and revisit }\end{array}$ \\
\hline Distribution & Exponential & Normal & Normal & Uniform & $\begin{array}{c}\text { Weekday: } 71 \% \\
\text { weekend: } 68 \%\end{array}$ \\
\hline
\end{tabular}

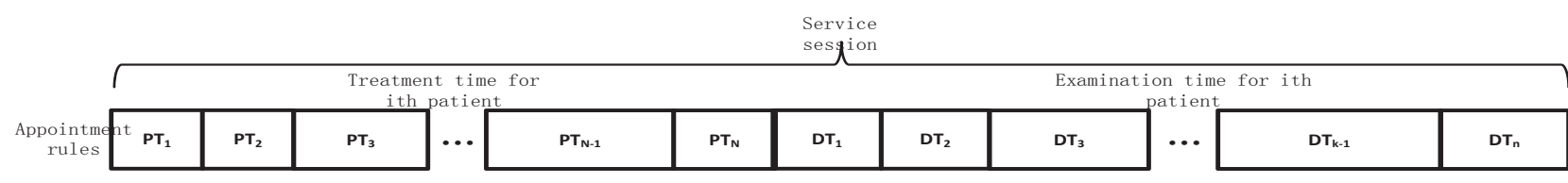

\begin{tabular}{|c|c|}
\hline Parameter & Explanation \\
\hline $\mathrm{i}$ & Index for each outpatient, $\mathrm{i}=1,2, \ldots, \mathrm{N}$ \\
\hline & Index for each patient of who \\
\hline $\mathrm{k}$ & $\begin{array}{l}\text { receives a medical examination using the } \\
\text { device, } \mathrm{k}=1,2, \ldots, \mathrm{n}\end{array}$ \\
\hline $\mathrm{j}$ & Index for each provider, $j=1,2, \ldots, \mathrm{M}$ \\
\hline WTPi & $\begin{array}{l}\text { Waiting time for patient } \mathrm{i} \text { before physician } \\
\text { assessment }\end{array}$ \\
\hline WTDk & $\begin{array}{l}\text { Waiting time for patient } \mathrm{k} \text { before } \\
\text { examination }\end{array}$ \\
\hline PIDTji & Idleness of provider $\mathrm{j}$ when treating patient $\mathrm{i}$ \\
\hline DIDTk & Idleness of device when testing patient $\mathrm{k}$ \\
\hline PTi & The time for physician assessment of patient $i$ \\
\hline DTk & The time for examination of patient $\mathrm{k}$ \\
\hline PIDT & Idleness of providers \\
\hline DIDT & Idleness of device \\
\hline IDT & Total idleness in system \\
\hline APWT & Average patient total waiting time \\
\hline
\end{tabular}

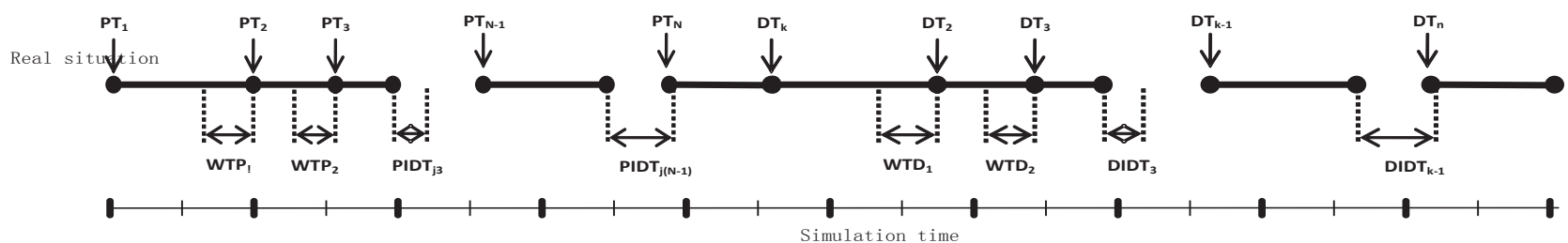

Fig. 4. Patient physician assessment and examination process

Table 7. Model parameters.

\subsection{Appointment Rule Design}

Appointment scheduling rules combine three factors: patient types, providers, and physician assessment times. After a comprehensive discussion on outpatient clinics in China, six rules were designed as follows:

- Rule 1: patients, both with fixed appointments and walk-ins, do not have a provider preference.

- Rule 2: no time restriction - patients with fixed appointments are served by Provider 1 while walk-ins are served by Providers 2 and 3 .

- Rule 3: patients with fixed appointments and walk-ins are served alternatively every 1 hour. All providers are available to both patient types.

- Rule 4: scheduled patients and walk-ins are served alternatively every 1 hour; patients with fixed appointments are served by Provider 1 while walk-ins are served by Providers 2 and 3 . 
- Rule 5: walk-ins and patients with fixed appointments are served separately, with the former in the morning and the latter in the afternoon. All providers are available to the two types of patients.

- Rule 6: walk-ins and scheduled patients are served separately, with the former in the morning and the latter in the afternoon. Patients with fixed appointments are served by Providers 1 and 2 while walk-ins are served by all providers.

\section{Simulation Results and Analysis}

In order to identify the optimal rule(s) that improve the performance of outpatient clinics, the proposed six scheduling rules are evaluated according to three performance measures. Then, sensitivity analysis is performed to provide the optimal values of the appointed physician assessment time and the percentage of walk-ins and scheduled patients.

\subsection{Model Verification and Validation}

To ensure the accuracy of the simulation results, a verification and validation of the simulation model is essential. In this section, the model is run repeatedly 10 times and each run lasts 49 hours. As shown in Table 8, the daily patient throughput is 140 , and utilizations of the device and the providers are about $97 \%$ and $45 \%$, respectively. When compared with the actual waiting time and utilization data, no significant difference was found. Therefore, it can be concluded that the model can accurately reflect the current situation. Also, during the simulation run, it was found that after the fifth day most measures became stable, suggesting that the model had reached a steady state. After reaching a steady state, the simulation experiments were carried out for each of the six scheduling rules, and then the data was recorded.

Table 8. Results of model verification and validation.

\begin{tabular}{|c|c|c|c|c|c|c|c|c|c|}
\hline Time & $\begin{array}{l}\text { Patient total } \\
\text { waiting time }\end{array}$ & $\begin{array}{c}\text { Patient } \\
\text { throughput }\end{array}$ & $\begin{array}{c}\text { Physician } \\
\text { assessment } \\
\text { area } \\
\text { utilization }\end{array}$ & $\begin{array}{c}\text { Device area } \\
\text { utilization }\end{array}$ & $\begin{array}{c}\text { Provider } \\
\text { utilization }\end{array}$ & $\begin{array}{l}\text { Device } \\
\text { idleness }\end{array}$ & $\begin{array}{l}\text { Idleness of } \\
\text { clinic } 1\end{array}$ & $\begin{array}{c}\text { Idleness } \\
\text { of clinic } \\
2\end{array}$ & $\begin{array}{l}\text { Idleness of } \\
\text { clinic } 3\end{array}$ \\
\hline 1 & 25583 & 140 & $97 \%$ & $95 \%$ & $46 \%$ & 22 & 14 & 12 & 17 \\
\hline 2 & 24503 & 140 & $97 \%$ & $95 \%$ & $47 \%$ & 21 & 15 & 12 & 16 \\
\hline 3 & 23332 & 140 & $96 \%$ & $95 \%$ & $47 \%$ & 21 & 16 & 12 & 16 \\
\hline 4 & 21298 & 140 & $97 \%$ & $95 \%$ & $43 \%$ & 22 & 15 & 13 & 14 \\
\hline 5 & 21252 & 140 & $97 \%$ & $95 \%$ & $45 \%$ & 22 & 14 & 15 & 15 \\
\hline 6 & 21252 & 140 & $97 \%$ & $95 \%$ & $45 \%$ & 22 & 14 & 15 & 15 \\
\hline 7 & 21252 & 140 & $97 \%$ & $95 \%$ & $45 \%$ & 22 & 14 & 15 & 15 \\
\hline
\end{tabular}

\subsection{Experimental Analysis and Results}

In this section, a comprehensive assessment and evaluation of the simulation results for the six rules was conducted based on three measures: patient total waiting time, provider utilization, and device utilization.

(1) Patient Waiting Time: The simulation results for patient waiting time are presented in Table 9. Obviously, patients under Rule 1 experience the longest waiting time in the system while patients under Rule 4 experience the shortest waiting time. The average throughput in one hour is the same for Rules 5 and 6. Rules 1 and 3 provide the smallest average throughput in one hour while Rule 4 results in the largest average throughput. As for the whole session, Rule 4 results in the largest throughput. It was also found that the average waiting time of Rule 1 is larger than all the other rules, while the average waiting time of Rule 4 is the shortest. In summary, Rule 4 is the most optimal rule.

(2) Device and Resource Utilization: The simulation results of device utilization are shown in Table 10.
For all the six rules, the utilizations of registration area, physician assessment area and examination area are high, indicating that the outpatient resources can be fully used with no serious concerns about their idleness under the proposed rules, especially in the examination area. The machine working time of the chest X-ray is almost the same for all rules. It was also found that Rules 1,3 , and 4 have the shortest idle times, indicating that resource utilization is high. For the block time, all rules are the same except for Rule 3 . Rule 4 is the most optimal rule when considering work/idle/block times.

(3) Medical Staff: As shown in Table 11, the utilization of providers varies between the six rules. For Rules 1 and 3, provider utilization is only $43-44 \%$. The remaining four rules provide more than $50 \%$ utilization, with Rule 4 providing the highest utilization at $54 \%$. Although there is no significant difference of the results for the utilization of nurses and registration staff among the six rules, Rule 4 is the most optimal because the two measures are slightly higher than the other rules. 
Table 9. Patient waiting time comparison.

\begin{tabular}{|c|c|c|c|c|c|}
\hline $\begin{array}{l}\text { Patient } \\
\text { Waiting }\end{array}$ & $\begin{array}{l}\text { State } \\
\text { Time }\end{array}$ & $\begin{array}{c}\text { Total Waiting } \\
\text { Time }(W T)\end{array}$ & $\begin{array}{c}\text { Average Patient } \\
\text { Throughput Per Hour }(n)\end{array}$ & $\begin{array}{l}\text { Patient Throughput in } \\
\text { Session }(=\mathrm{n} * 7)\end{array}$ & $\begin{array}{c}\text { Average Patient Waiting } \\
\text { Time }(\mathrm{APWT}=(\mathrm{WT} / N))\end{array}$ \\
\hline Rule 1 & 145 & 20630 & 18 & 126 & 163.648 \\
\hline Rule 2 & 121 & 18507 & 20 & 140 & 132.195 \\
\hline Rule 3 & 114 & 15944 & 18 & 126 & 126.542 \\
\hline Rule 4 & 99 & 15775 & 22 & 154 & 102.238 \\
\hline Rule 5 & 124 & 19202 & 21 & 147 & 130.626 \\
\hline Rule 6 & 134 & 20931 & 21 & 147 & 142.390 \\
\hline
\end{tabular}

Table 10. Resource and device utilization.

\begin{tabular}{|c|c|c|c|c|c|c|c|c|}
\hline \multirow[b]{2}{*}{ Rule } & \multicolumn{2}{|c|}{ Utilization } & \multicolumn{3}{|c|}{ Chest X-ray } & \multicolumn{3}{|c|}{ Clinic } \\
\hline & $\begin{array}{c}\text { Physician } \\
\text { Assessment } \\
\text { Area }\end{array}$ & $\begin{array}{c}\text { Examination } \\
\text { Area }\end{array}$ & $\begin{array}{l}\text { Work } \\
\text { Time }\end{array}$ & $\begin{array}{l}\text { Idle } \\
\text { Time }\end{array}$ & $\begin{array}{l}\text { Block } \\
\text { Time }\end{array}$ & $\begin{array}{l}\text { Work } \\
\text { Time }\end{array}$ & $\begin{array}{l}\text { Idle } \\
\text { Time }\end{array}$ & $\begin{array}{c}\text { Block } \\
\text { Time }\end{array}$ \\
\hline Rule 1 & $96 \%$ & $93 \%$ & 388 & 28 & 3 & 120 & 16 & 284 \\
\hline Rule 2 & $93 \%$ & $93 \%$ & 388 & 29 & 3 & 129 & 49 & 252 \\
\hline Rule 3 & $95 \%$ & $93 \%$ & 389 & 28 & 4 & 124 & 18 & 277 \\
\hline Rule 4 & $95 \%$ & $93 \%$ & 389 & 28 & 3 & 121 & 15 & 285 \\
\hline Rule 5 & $95 \%$ & $93 \%$ & 386 & 31 & 3 & 133 & 20 & 267 \\
\hline Rule 6 & $95 \%$ & $93 \%$ & 386 & 30 & 3 & 133 & 19 & 268 \\
\hline
\end{tabular}

Table 11. Staff utilization.

\begin{tabular}{cccc}
\hline $\begin{array}{c}\text { Staff } \\
\text { Utilization }\end{array}$ & $\begin{array}{c}\text { Provider } \\
\text { Utilization }\end{array}$ & $\begin{array}{c}\text { Nurse } \\
\text { Utilization }\end{array}$ & $\begin{array}{c}\text { Registration staff } \\
\text { Utilization }\end{array}$ \\
\hline Rule 1 & $44 \%$ & $62 \%$ & $34 \%$ \\
Rule 2 & $53 \%$ & $63 \%$ & $38 \%$ \\
Rule 3 & $43 \%$ & $62 \%$ & $34 \%$ \\
Rule 4 & $\mathbf{5 4 \%}$ & $\mathbf{6 4 \%}$ & $\mathbf{3 9 \%}$ \\
Rule 5 & $51 \%$ & $63 \%$ & $38 \%$ \\
Rule 6 & $51 \%$ & $63 \%$ & $38 \%$ \\
\hline
\end{tabular}

From the evaluation and comparison of patient waiting times, and device and provider utilizations, it was found that when patients with fixed appointments and walk-ins are considered at the same time under outpatient settings, Rule 4 provides the most optimal results. After comprehensively evaluating all the rules, Rule 4 is found to provide the best results overall.

\subsection{Sensitivity Analysis}

Although the best scheduling rule has been chosen, two vital parameters need to be determined specifically for Chinese settings: the percentage of patients with fixed appointments and walk-ins, and scheduled physician assessment time. Therefore, sensitivity analysis is conducted for these two parameters. The effect on performance measures, which results from the interaction of the two parameters, has been be analyzed. The percentages tested were set to $10-90 \%, 20-80 \%, 30-70 \%$, $40-60 \%, 50-50 \%, 60-40 \%, 70-30 \%, 80-20,90-10 \%$, and scheduled times (in minutes) to $5,10,20,30,40,50$, and 60. The simulation experiments were designed for Rule 4.

The resulting total waiting times are listed in Table 12, which shows that when the percentage of patients with fixed appointment and walk-ins is $30-70 \%$, and the scheduled service time is 20 minutes, the total waiting time is at its smallest value. However, when the percentage is $90-10 \%$, and the scheduled service time is 60 minutes, the total waiting time is at its largest. In addition, the two second-best combinations are: $20-80 \%$ and $20 \mathrm{~min} ; 40-60 \%$ and $15 \mathrm{~min}$. The optimal result is when the percentages of patients with fixed appointments and walk-ins are $20-80 \%, 30 \%-70 \%, 40-60 \%$ or $50-50 \%$, and scheduled service times are $15 \mathrm{~min}$ and $20 \mathrm{~min}$. This indicates that under outpatient settings, if the percentage of scheduled patients is set relatively low, and scheduled time is shorter, then the total patient waiting time will be minimized.

For device utilization, shown in Table 13, when the two parameters vary simultaneously, their interaction has little influence. Regardless of the combination, utilization remains around $90 \%$, implying that the device could be a bottleneck. Also, when the percentage of patients with fixed appointments and walk-ins is 10-90\%, and scheduled service time is $50 \mathrm{~min}$, the device utilization is at its highest. However, when the percentage of patients with fixed appointments and walk-ins is 60-40\%, and scheduled service time is $10 \mathrm{~min}$, the device utilization is at its lowest. Second-best combinations are: $40-60 \%$ and $15 \mathrm{~min}$, and $50-50 \%$ and $5 \mathrm{~min}$.

The total idle times of providers and devices are summarized in Table 14. The shortest idle time is found when the percentage of patients with fixed appointments and walk-ins is $30-70 \%$, and the scheduled service time is $20 \mathrm{~min}$. The longest is found when the percentage of patients with fixed appointments and walk-ins is set to 90$10 \%$, and the scheduled service time at $60 \mathrm{~min}$. Potential optimal combinations are: $30-70 \%$ and $30 \mathrm{~min}$, and $40 \%$ $60 \%$ and $20 \mathrm{~min}$.

The top three optimal combinations for every performance measure are listed in Table 15. For the combinations of $50-50 \%$ and $5 \mathrm{~min}$, and $10-90 \%$ and 50 min, under the two settings the device utilization is high, yet the patient waiting time and total idle time is much worse than in other schemes. Therefore, those two combinations are ignored. For the combination 30-70\% 
and $30 \mathrm{~min}$, the total idle time is low, yet the patient total waiting time is relatively high, and the device utilization is lower than in other alternatives. As for the remaining options, for $40-60 \%$ and $20 \mathrm{~min}$, the total waiting time is high. For $20-80 \%$ and $20 \mathrm{~min}$ and $40-60 \%$ and $15 \mathrm{~min}$, the total idle times are also somewhat high. In summary, 30$70 \%$ and $20 \mathrm{~min}$ is the optimal combination. It is recommended not only in terms of total waiting time, but also in total idleness (with the utilization being only a little lower than the best one).

Table 12. Patient total waiting time.

\begin{tabular}{|c|c|c|c|c|c|c|c|c|c|}
\hline \multirow{2}{*}{$\begin{array}{l}\text { The percentage of } \\
\text { appointment patients and } \\
\text { walk-in patients }\end{array}$} & \multicolumn{8}{|c|}{ Scheduled Times } & \\
\hline & $5 \mathrm{~min}$ & $10 \mathrm{~min}$ & $\begin{array}{c}15 \\
\text { min }\end{array}$ & $\begin{array}{c}20 \\
\min \end{array}$ & $\begin{array}{c}30 \\
\text { min }\end{array}$ & $\begin{array}{c}40 \\
\min \end{array}$ & $\begin{array}{c}50 \\
\text { min }\end{array}$ & $60 \mathrm{~min}$ & \\
\hline $10 \%-90 \%$ & 23321 & 23010 & 19958 & 17022 & 24792 & 24792 & 25378 & 25963 & \\
\hline $20 \%-80 \%$ & 19327 & 22444 & 17778 & 15842 & 23598 & 23598 & 24418 & 24751 & \\
\hline $30 \%-70 \%$ & 20482 & 20915 & 16463 & 14987 & 19933 & 20931 & 22584 & 23966 & \\
\hline $40 \%-60 \%$ & 21102 & 18959 & 15775 & 16581 & 20688 & 21988 & 23692 & 24221 & \\
\hline $50 \%-50 \%$ & 21212 & 18564 & 17019 & 17297 & 21867 & 22867 & 24360 & 24859 & \\
\hline $60 \%-40 \%$ & 21376 & 19278 & 18162 & 19051 & 22737 & 22937 & 24983 & 25478 & \\
\hline $70 \%-30 \%$ & 22456 & 20772 & 19519 & 20777 & 22748 & 23548 & 25784 & 26288 & \\
\hline $80 \%-20 \%$ & 22792 & 21669 & 21671 & 21999 & 23551 & 23752 & 26332 & 26954 & \\
\hline $90 \%-10 \%$ & 23835 & 22758 & 22963 & 22854 & 23974 & 24582 & 26915 & 27753 & \\
\hline \multicolumn{10}{|c|}{ Table 13. Device utilization. } \\
\hline \multirow{2}{*}{$\begin{array}{l}\text { The percentage of appointment } \\
\text { patients and walk-in patients }\end{array}$} & \multicolumn{9}{|c|}{ Scheduled Times } \\
\hline & $5 \mathrm{~min}$ & $10 \mathrm{~min}$ & $15 \mathrm{~min}$ & & & $0 \mathrm{~min}$ & $40 \mathrm{~min}$ & $50 \mathrm{~min}$ & $60 \mathrm{~min}$ \\
\hline $10 \%-90 \%$ & $92 \%$ & $91 \%$ & $90 \%$ & & & $89 \%$ & $89 \%$ & $99 \%$ & $85 \%$ \\
\hline $20 \%-80 \%$ & $92 \%$ & $89 \%$ & $89 \%$ & & & $89 \%$ & $90 \%$ & $86 \%$ & $89 \%$ \\
\hline $30 \%-70 \%$ & $91 \%$ & $91 \%$ & $88 \%$ & & & $88 \%$ & $79 \%$ & $86 \%$ & $90 \%$ \\
\hline $40 \%-60 \%$ & $90 \%$ & $88 \%$ & $93 \%$ & & & $91 \%$ & $89 \%$ & $89 \%$ & $88 \%$ \\
\hline $50 \%-50 \%$ & $93 \%$ & $92 \%$ & $87 \%$ & & & $90 \%$ & $90 \%$ & $90 \%$ & $85 \%$ \\
\hline $60 \%-40 \%$ & $92 \%$ & $77 \%$ & $90 \%$ & & & $90 \%$ & $88 \%$ & $88 \%$ & $85 \%$ \\
\hline $70 \%-30 \%$ & $91 \%$ & $88 \%$ & $91 \%$ & & & $91 \%$ & $91 \%$ & $88 \%$ & $90 \%$ \\
\hline $80 \%-20 \%$ & $90 \%$ & $92 \%$ & $90 \%$ & & & $91 \%$ & $90 \%$ & $90 \%$ & $86 \%$ \\
\hline $90 \%-10 \%$ & $91 \%$ & $85 \%$ & $92 \%$ & & & $92 \%$ & $88 \%$ & $86 \%$ & $89 \%$ \\
\hline
\end{tabular}

Table 14. Total idleness of providers and device.

\begin{tabular}{|c|c|c|c|c|c|c|c|c|}
\hline \multirow{2}{*}{$\begin{array}{l}\text { The percentage of } \\
\text { appointment patients } \\
\text { and walk-in patients }\end{array}$} & \multicolumn{8}{|c|}{ scheduled times } \\
\hline & $\begin{array}{l}\text { Scheduled } \\
\text { Times }\end{array}$ & $10 \mathrm{~min}$ & $15 \mathrm{~min}$ & $20 \mathrm{~min}$ & $30 \mathrm{~min}$ & $40 \mathrm{~min}$ & $50 \mathrm{~min}$ & $60 \mathrm{~min}$ \\
\hline $10 \%-90 \%$ & $5 \mathrm{~min}$ & $10 \mathrm{~min}$ & $15 \mathrm{~min}$ & $20 \mathrm{~min}$ & $30 \mathrm{~min}$ & $40 \mathrm{~min}$ & $50 \mathrm{~min}$ & $60 \mathrm{~min}$ \\
\hline $10 \%-90 \%$ & $92 \%$ & $91 \%$ & $90 \%$ & $92 \%$ & $89 \%$ & $89 \%$ & $99 \%$ & $85 \%$ \\
\hline $20 \%-80 \%$ & $92 \%$ & $89 \%$ & $89 \%$ & $91 \%$ & $89 \%$ & $90 \%$ & $86 \%$ & $89 \%$ \\
\hline $30 \%-70 \%$ & $91 \%$ & $91 \%$ & $88 \%$ & $91 \%$ & $88 \%$ & $79 \%$ & $86 \%$ & $90 \%$ \\
\hline $40 \%-60 \%$ & $90 \%$ & $88 \%$ & $93 \%$ & $92 \%$ & $91 \%$ & $89 \%$ & $89 \%$ & $88 \%$ \\
\hline $50 \%-50 \%$ & $93 \%$ & $92 \%$ & $87 \%$ & $88 \%$ & $90 \%$ & $90 \%$ & $90 \%$ & $85 \%$ \\
\hline $60 \%-40 \%$ & $92 \%$ & $77 \%$ & $90 \%$ & $90 \%$ & $90 \%$ & $88 \%$ & $88 \%$ & $85 \%$ \\
\hline $70 \%-30 \%$ & $91 \%$ & $88 \%$ & $91 \%$ & $91 \%$ & $91 \%$ & $91 \%$ & $88 \%$ & $90 \%$ \\
\hline $80 \%-20 \%$ & $90 \%$ & $92 \%$ & $90 \%$ & $90 \%$ & $91 \%$ & $90 \%$ & $90 \%$ & $86 \%$ \\
\hline $90 \%-10 \%$ & $91 \%$ & $85 \%$ & $92 \%$ & $92 \%$ & $92 \%$ & $88 \%$ & $86 \%$ & $89 \%$ \\
\hline
\end{tabular}

Table 15. Comparison of optimal combinations.

\begin{tabular}{cccc}
\hline Combination & $\begin{array}{c}\text { Total Waiting } \\
\text { Time }\end{array}$ & $\begin{array}{c}\text { Device } \\
\text { Utilization }\end{array}$ & $\begin{array}{c}\text { Total } \\
\text { Idleness }\end{array}$ \\
\hline $30 \%-70 \%$ \& $20 \mathrm{~min}$ & $\mathbf{1 4 9 8 7}$ & $\mathbf{9 1 \%}$ & $\mathbf{1 1 8}$ \\
$20 \%-80 \%$ \& $20 \mathrm{~min}$ & 15842 & $91 \%$ & 132 \\
$40 \%-60 \%$ \& $15 \mathrm{~min}$ & 15775 & $93 \%$ & 132 \\
$50 \%-50 \%$ \& $5 \mathrm{~min}$ & 21212 & $93 \%$ & 184 \\
$10 \%-90 \%$ \& $50 \mathrm{~min}$ & 25378 & $99 \%$ & 186 \\
$30 \%-70 \%$ \& $30 \mathrm{~min}$ & 19933 & $88 \%$ & 122 \\
$40 \%-60 \%$ \& $20 \mathrm{~min}$ & 16581 & $92 \%$ & 125 \\
\hline
\end{tabular}

\section{Conclusions and Future Work}

This research developed an outpatient appointment scheduling model for the Chinese healthcare system. The model was developed for a multi-provider clinic with a single device with follow-up procedures. This research also designed and evaluated six scheduling rules based on the medical environment in China. This research is especially significant because it considers multiple providers, a single device examination, and revisit procedures. In addition, the six scheduling rules were designed to include both walk-ins and patients with fixed appointments.

The simulation model was built in FlexSim HC and was used to simulate the proposed rules with the same parameter settings. After an evaluation of the comprehensive simulation results, the following 
conclusions were drawn: when considering both walk-ins and scheduled patients, Rule 4 led to the shortest waiting time, and the highest device and staff utilization. Under this rule, patients with fixed appointments and walk-ins are served alternatively every 1 hour. Patients with fixed appointments are served by Provider 1, while walk-ins are served by Providers 2 and 3. The sensitivity analysis under Rule 4 showed that when the percentage of patients with fixed appointments and walk-ins, and scheduled service time is $30-70 \%$ and $20 \mathrm{~min}$, the values of the two parameters are the most optimal.

Although the research identifies effective proposals for optimal scheduling rules, there are some limitations. First, the time period for the data collection is short, yielding an insufficient amount of data. Second, the study only focuses on chest X-ray examination, when in reality there are a number of different types of examinations available in internal medical clinics. Also, patients can also potentially have more than one revisit. Finally, the proposed scheduling rules are fairly simple and only account for certain attributes.

Therefore, future research could focus on several ideas. In addition to collecting more data and adding multiple examinations and revisits into the system, the addition of more complex factors into the scheduling rules, such as patient preference and punctuality, can also be studied. Another direction of future research could examine specific scheduling rules of the medical devices. Finally, a more thorough study of scheduling rules, the percentage of patients with fixed appointments, and scheduled service times, can provide valuable insight to assist in improving the overall scheduling systems of outpatient clinics.

\section{Acknowledgment}

This work is supported by National Natural Science Foundation of China (71302169), Natural Science Foundation of Hebei (F2009000111) and Social Science Foundation of the Ministry of Education (12YJC630235).

\section{References}

1. Luo, X., Kong, L., Zhu, G. Survey of treatment time in outpatient clinics. Medicine and Society, 2002, 15(2): 63-64 (in Chinese).

2. Liu, F., Liu, M. The application of flow analysis technique in healthcare service. Chinese Hospital Management, 2004, 24(1): 57-58 (in Chinese).

3. $\mathrm{Xu}, \mathrm{S}$. The study of medical process with simulation analysis in out-patient department. Sichuan University, 2007 (in Chinese).

4. Chang, W., Peng, Y., Tong, S. The application of queuing theory in efficiency of service process in outpatient registration and shroff office. Chinese Hospital Management, 2005, 21(12):814-818 (in Chinese).

5. Chen, Y., Li, X., Tang, S. Patient flow measurement of different services during various periods in outpatient clinics. China Health Statistics, 2005, 22(5): 341-342 (in Chinese).

6. Lindley, D. V. The theory of queues with a single server. Mathematical Proceedings of the Cambridge Philosophical Society. Cambridge University Press, 1952, 48(02): 277-289.

7. Mercer, A. Queues with scheduled arrivals: A correction, simplification and extension. Journal of the Royal Statistical Society, Series B (Methodological), 1973: 104-116.

8. Soriano, A. Comparison of two scheduling system. Operations Research, 1966, 14(3): 388-397.

9. Fries, B. E., Marathe, V. P. Determination of optimal variable-sized multiple-block appointment systems. Operations Research, 1981, 29(2): 324-345.

10. Liao, C. J, Pegden, C. D, Rosenshine, M. Planning timely arrivals to a stochastic production or service system. IIE Transactions, 1993, 25(5): 63-73.

11. Liu, L., Liu, X. Dynamic and static job allocation for multi-server systems. IIE Transactions, 1998, 30(9): 845 854.

12. Mahachek, A. R, Knabe, T. L. Computer simulation of patient flow in obstetrical/gynecology clinics. Simulation, 1984, 43(2): 95-101.

13. Bailey, N. T. J. A study of queues and appointment systems in hospital out-patient departments, with special reference to waiting-times. Journal of the Royal Statistical Society. Series B (Methodological), 1952: 185-199.

14. Welch, J. D, Bailey, N. T. J. Appointment systems in hospital outpatient departments. The Lancet, 1952, 259(6718): 1105-1108.

15. O'Keefe, R. Investigating Outpatient Departments: Implementable Policies and Qualitative Approaches. Journal of the Operational Research Society, 1985,36( 8): 705-712

16. Fetter, R. B., Thompson, J. D. Patients' waiting time and doctors' idle time in the outpatient setting. Health Services Research, 1966, 1(1): 66.

17. White, M. J. B., Pike, M. C. Appointment systems in out-patients' clinics and the effect of patients' unpunctuality. Medical Care, 1964: 133-145.

18. Swisher, J. R., Jacobson, S. H., Jun, J. B., Balci, O. Modeling and analyzing a physician clinic environment using discrete-event (visual) simulation. Computers \& Operations Research, 2001, 28(2): 105-125.

19. Rising, E. J, Baron, R., Averill, B. A systems analysis of a university-health-service outpatient clinic. Operations Research, 1973, 21(5): 1030-1047.

20. Brahimi, M., Worthington, D. J. The finite capacity multi-server queue with inhomogeneous arrival rate and discrete service time distribution - and its application to continuous service time problems. European Journal of Operational Research, 1991, 50(3): 310-324

21. Gupta, D., Denton, B. Appointment scheduling in health care: Challenges and opportunities. IIE Transactions, 2008, 40:800-819. 
22. Cayirli, T., Veral, E. Outpatient scheduling in health care: a review of literature. Production and Operations Management, 2003, 12(4): 519-549.

23. Ho, C.-J., Lau, H.-S. Minimizing total cost in scheduling outpatient appointments. Management Science, 1992, 38(12): 1750-1764.

24. Robinson, L., Chen, R. Scheduling doctors' appointments: optimal and empirically based heuristic policies. IIE Transactions, 2003, 35(3): 295-307.

25. Vanden, B. P. M., Dietz, D. C. Minimizing expected waiting in a medical appointment system. IIE Transactions, 2000, 32(9): 841-848

26. Jansson, B. Choosing a good appointment system-A study of queues of the type (D, M, 1). Operations Research, 1966, 14(2): 292-312.

27. Wang, P. P. Static and dynamic scheduling of customer arrivals to a single server system. Naval Research Logistics (NRL), 1993, 40(3): 345-360.

28. Klassen, K. J., Rohleder, T. R. Scheduling outpatient appointments in a dynamic environment. Journal of Operations Management, 1996, 14(2): 83-101.

29. Mondschein, S, Weintraub, G. Appointment policies in service operations: a critical analysis of the economic framework. Production and Operations Management, 2003, 12(2): 266-286

30. Murray, M., Tantau, C. Same-Day Appointment: Exploding the Access Paradigm. An FPM Classic, 2000.

31. Murray, M., Berwick, D. M. Advanced access. Journal of the American Medical Association, 2003, 289(8): 10351040 .

32. Murray, M., Tantau, C. Redefining open access to primary care. Managed Care Quarterly, 1999, 7: 45-55.

33. Fries, B. E., Marathe, V. P. Determination of optimal variable-sized multiple-block appointment systems. Operations Research, 1981, 29(2): 324-345.

34. Cayirli, T., Veral, E., Rosen, H. Designing appointment scheduling systems for ambulatory care services. Health Care Management Science, 2006, 9: 47-58

35. Harper, P., Gamlin, H. Reduced outpatient waiting times with improved appointment scheduling: a simulation modeling approach. OR Spectrum, 2003, 25: 207-222

36. Patrick, J., Putmeran, M., Queyranne, M. Dynamic multi-priority patient scheduling for a diagnostic resource. Operations Research, 2008, 56(6).

37. Koizumi, N., Kuno, E., Smith, T. E. Modeling patient flows using a queuing network with blocking. Health Care Manage Science, 2008, 8(1): 49-60

38. Babes, M., Sarma, G. Outpatient queues at the IbnRochd health centre. Journal of the Operational Research Society, 1991, 42(10): 845-855.

39. Kopach, R., DeLaurentis, P. C., Lawley, M., Muthuraman, Ozsen, L., Rardin, R., Wan, H., Intrevado, P., Qu, X., Willis, D. Effects of clinical characteristics on successful open access scheduling. Health Care Management Science, 2007, 10(2): 111-124.

40. Kim, S, Giachetti, R. E. A stochastic mathematical appointment overbooking model for healthcare providers to improve profits. Systems, Man and Cybernetics, Part A: Systems and Humans, IEEE Transactions on, 2006, 36(6): 1211-1219.

41. Lawley, M., Muthuraman, K. A stochastic overbooking model for outpatient clinical scheduling with no-shows. IIE Transactions, 2007, 40: 820-837.

42. LaGanga, L. R., Lawrence, S. R. Clinic overbooking to improve patient access and increase provider productivity. Decision Sciences, 2007, 38(2): 251-276.

43. Cayirli, T., Veral, E., Rosen, H. Designing appointment scheduling systems for ambulatory care services. Health Care Management Science, 2006, 9(1): 47-58.

44. Green, L. V., Savin, S, Wang, B. Managing patient service in a diagnostic medical facility. Operations Research, 2006, 54(1): 11-25.

45. Gupta, D., Wang, L. Revenue management for a primary care clinic in the presence of patient choice. Operations Research, 2007, 576-592 